\title{
Measuring Ownership, Control, and Use of Assets
}

\author{
Cheryl R. Doss \\ University of Oxford - Department of International Development
}

Caitlin Kieran

University of California, Davis - Department of Agricultural and Resource Economics, Students

Talip Kilic

World Bank - Development Data Group (DECDG)

Forthcoming in Feminist Economics

\begin{abstract}
Assets generate and help diversify income, alleviate liquidity constraints, and are key inputs into empowerment. Despite the importance of individual-level data on asset ownership, and the fact that most assets are owned by individuals, either solely or jointly, it is typical for the micro data on asset ownership to be collected at the household-level. Through a review of the existing approaches to data collection and the relevant literature on survey methodology, we present an overview of the current best practices for collecting individual-level data on the ownership and control of assets in household and farm surveys. The paper provides recommendations in three areas: (1) respondent selection, (2) definition and measurement of access to and ownership and control of assets, and (3) measurement of quantity, value, and quality of assets. We identify open methodological questions that can be answered through further research.
\end{abstract}

JEL Codes: C83, D31, J16.

Keywords: Gender, Asset Ownership, Wealth, Survey Methodology, Household Surveys. 


\section{Introduction}

Ownership and control of physical and financial assets are essential to an individual's wellbeing. Assets generate and help diversify income; provide collateral to gain access to credit; alleviate liquidity constraints in the face of shocks; and provide status in society (Deere and Doss, 2006). They also provide a means for people to smooth consumption over time. A large body of literature demonstrates the critical role that assets, and not just income, play in poverty reduction (see Johnson et al. (2016) for a review). Although economic research focused on asset ownership and wealth has traditionally assessed household asset portfolios, an increasing number of studies over the last decade have emphasized the importance of the collection and analysis of individual-level information on ownership and control of physical and financial assets. This represents an important shift because it acknowledges that men and women often have differential access to, control over, and ability to benefit from assets.

The empirical utility of high-quality, individual-level data on asset ownership and control cannot be overstated. First, these data enrich the analyses of gender differences in wealth, revealing the extent of economic disadvantage accumulated by women over the life cycle and providing a long-term and more holistic overview of the gender dimensions of economic inequality (Warren, 2006; Deere and Doss, 2006; Sierminska, Frick, and Grabka, 2010; Ruel and Hauser, 2013; Doss et al., 2014; Hillesland, 2018). Second, in comparison to household-level analyses, asset studies focused on individuals provide more nuanced insights into the determinants of poverty and vulnerability by capturing additional vulnerabilities faced by women, ${ }^{1}$ whose rights over asset often disappear upon dissolution of her household whether due to death, divorce, or separation. Third, the desired individuallevel data directly inform microeconomic research that focuses on women's empowerment and intrahousehold bargaining and cooperation and that often utilizes control of assets as a proxy for individual's empowerment/bargaining power. Evidence suggests that the decisions made within the household are different when women have higher bargaining power and that the outcomes generally increase the well-being of women and their children (Allendorf, 2007; Beegle et al., 2001; Deininger et al., 2010; Doss, 2006; Duflo, 2003; Haddad et al., 1997; Menon et al., 2014; Quisumbing and Maluccio, 2003; Thomas, 1990). Finally, understanding who uses and controls assets is crucial for appropriate design and targeting of livelihood interventions to not only enhance the productivity of farmers and

\footnotetext{
${ }^{1}$ For instance, Quisumbing et al. (2011) find that, in Bangladesh, weather-related shocks impact men's assets more than women's assets, but shocks related to illness have a larger impact on women's assets. In Uganda, drought shocks affect women's assets, but not men's assets.
} 
entrepreneurs but also ensure that these interventions do not have unintended consequences. $^{2}$

Despite the importance of individual-level data on asset ownership and control, and the fact that most assets are owned by individuals, either solely or jointly, it is typical for the micro data on asset ownership to be collected largely at the household-level (Doss et al., 2008; Deere et al., 2012; Ruel and Hauser, 2013). Even when household survey data are collected at the individual-level, with identification of reported or documented owners of a given asset within the same household, the information is often collected from a single respondent, often the household member designated as the "most knowledgeable" household member. Further, data on ownership are seldom paired with data identifying individuals who hold specific rights to assets, limiting our understanding of the interrelationships among ownership and rights, and whether these relationships vary across individuals (Kilic and Moylan, 2016).

Accurate measurement of ownership, control, and use of assets is essential for diagnosing problems and developing recommendations to address these challenges within developing countries. Although sex-disaggregated asset ownership indicators are part of the data agenda for the Sustainable Development Goals (SDGs), gaps remain in our knowledge of how best to collect these data. Identifying the best practices on questionnaire design and respondent selection protocols is in turn necessary to promote the availability and comparability of these indicators on a cross-country basis (Kilic and Moylan, 2016).

Gendered analysis of asset ownership, control, and use can promote the development of livelihood interventions that are more gender aware or gender transformative. For example, the Gender, Agriculture, and Assets Project (GAAP) worked with eight agricultural development projects in Africa and South Asia to develop monitoring and evaluation plans that focus on gendered asset ownership. Half of the projects significantly increased women's assets, but only one of the four projects successfully reduced the gender asset gap. Since project benefits are often reinvested in assets controlled by men, some of these projects also increased men's assets. Conducting a gendered analysis of asset rights thus revealed that even distributing assets directly to women does not necessarily shrink the gap

\footnotetext{
${ }^{2}$ Evidence has demonstrated that secure land rights increase agricultural production at the household level, but very little research exists on this topic at the individual level. Goldstein and Udry (2008) find that in Ghana, women farmers had less secure land rights than men, and were thus less likely to leave their land fallow due to their increased risk of losing land that they were not actively farming. Quisumbing et al. (2001) reveal also in Ghana that women were more likely to invest in land with secure property rights by planting cocoa trees. While more research is needed to understand the conditions under which strengthening women's property rights will increase aggregate agricultural productivity and sustainable management practices (Doss, 2017), sufficient evidence has demonstrated that livelihood interventions that do not recognize the gender asset gap run the risk of exacerbating inequalities (Meinzen-Dick et al., 2014). See also O'Sullivan's review of gender and property rights in Africa.
} 
in assets between men and women, suggesting that projects must work to transform norms that weaken women's control of assets (Johnson et al., 2016). Several recent efforts have used different approaches to individual level asset data collection and analysis. They range from projects designed to demonstrate the feasibility and importance of collecting sexdisaggregated asset data, namely the Gender Asset Gap Project and the Methodological Experiment on Measuring Asset Ownership from a Gender Perspective (MEXA), to multipurpose surveys that include a few questions on asset ownership, such as the Demographic and Health Survey (DHS) and the Living Standards Measurement Study - Integrated Surveys on Agriculture (LSMS-ISA), and those that focus on a single type of asset, such as the Global Findex. The Women's Empowerment in Agriculture Index (WEAI) surveys collect data on ownership of productive assets as one domain of empowerment. In addition, the Gender, Assets and Agriculture Project (GAAP 2) identified ways to collect individual level asset data for project evaluation. Based on a comparative review of the published literature and current fieldwork practices of the relevant survey efforts, this paper (i) presents the best practices for collecting individual-level data on the ownership, control, and use of assets in the context of household and farm surveys, and (ii) identifies key gaps in our current knowledge. In pursuing these objectives, we aim to provide operational insights for survey practitioners and researchers in a consolidated fashion that facilitates the adoption and proliferation of best practices.

Tension always exists between trying to collect data that are internationally comparable and to ensure that they are also locally relevant. For the data to be internationally comparable, it is critical to have a shared understanding of the definition of ownership, even if it is measured differently across contexts. In each local context, it may be different assets that support livelihoods and thus for these analyses, local relevance may be more important than direct comparability across locations.

\section{Conceptual Framework}

Before assessing the state of knowledge on asset measurement, it is important to lay out the key conceptual issues. First, we must define assets, which generally refer to resources controlled by individuals, households, or formal or informal groups (see Johnson et al. (2016) for a review of asset definitions). They serve as a means of storing value and may provide a stream of benefits over time.

We focus our review on natural (specifically land and trees) ${ }^{3}$, physical, and financial assets. While human and social capital are important for understanding mechanisms to reduce poverty, increase women's empowerment, and improve livelihoods, methods of measuring

\footnotetext{
${ }^{3}$ Although water is also important, the access to and control over water is a substantially different issue with an extensive literature that is beyond the scope of this paper.
} 
human capital, have been widely studied, including from a gender perspective. The approaches to studying social capital require methods that differ considerably from those used for studying natural, physical, and financial assets. In addition, we exclude the analysis of access to and control over common property resources, mainly due to our pragmatic focus on areas in which cross-country applicable recommendations could be provided. ${ }^{4}$

The assets to be included will depend on the purpose of the survey as well as the context. If the goal is to calculate the gender wealth gap, then the focus can be on those assets with relatively higher values, such as land, housing, financial assets, and business assets. If the goal is to understand how assets are related to poverty, then it would be necessary to collect detailed data on the ownership of assets owned by the poor that are used to generate incomes, such as cooking pots or hand tools for agriculture. Information on the context in which data are collected can also influence which assets to include. For example, while most survey questionnaires in the first round of GAAP inquired about land, livestock, consumer durables, and agricultural assets, only surveys of projects in South Asia collected information on jewelry because previous research suggested that it is a key marker of status and a store of wealth (Johnson et al., 2016). Before embarking upon a quantitative survey, researchers should review existing literature, conduct qualitative field work, and work with local researchers to customize the survey to a specific context.

Although a livelihoods perspective might promote a focus on productive assets, such as land, dwelling, livestock, and, agricultural equipment, a bargaining perspective would encourage us to also consider other assets that may be of value, especially to women, such as jewelry. To understand how individuals accumulate assets as they move out of poverty - and how the accumulation of assets propels the movement out of poverty - it is important to consider not only those assets that have high value, such as land and livestock, but also those that have less economic value, and which may contribute to livelihoods or well-being such as consumer durables and smaller agricultural equipment items. For example, focus group discussions conducted as part of a GAAP project in India revealed the importance of expensive clothes, which help individuals attend events and build social capital (Johnson et al., 2016). Many of these smaller items, including household appliances and furniture, may belong to women and may be used in their income-generating activities. A gendered approach to data collection would capture the relevant assets for women in the particular context.

\footnotetext{
${ }^{4}$ Common property could include forests, rangelands, or water systems. The extent to which these assets are controlled by men, women, or jointly, as well as the resulting implications for livelihood strategies or empowerment (such as through leadership in the group tasked with the common property management) can be explored (Meinzen-Dick et al., 2014).
} 
There are myriad definitions of ownership, control, and use of assets; they represent the wide variety of rights over assets. Schlager and Ostrom (1992) characterize different bundles of rights along a continuum from access or use rights to control rights to ownership rights. Use rights might include the right to access the resource (e.g. walk across a field), withdraw from a resource (e.g. pick wild plants), or exploit a resource for economic benefit (e.g. fish commercially). Control or decision-making rights include the rights of management (e.g. plant a crop), exclusion (i.e. prevent others from accessing a resource), or alienation (e.g. rent out, sell, or give away the rights) (CAPRi, 2010). Transfer rights, including bequeathing, as well as the ability to distribute benefits from the assets, may also be considered control or decision-making rights.

A major challenge in measuring asset ownership is that the approaches necessarily vary substantially by asset type and by context. Understanding the definition of ownership in each setting requires an understanding of what rights are generally associated with ownership. This may include the full bundle of use and control rights or it may be defined as the right of alienation. The System of National Accounts uses two definitions of ownership, distinguishing between the legal owner and the economic owner.

"The legal owner of entities such as goods and services, natural resources, financial assets and liabilities is the institutional unit entitled in law and sustainable under the law to claim the benefits associated with the entities. By contrast, the economic owner of entities such as goods and services, natural resources, financial assets and liabilities is the institutional unit entitled to claim the benefits associated with the use of the entity in question in the course of an economic activity by virtue of accepting the associated risks" (UN Statistics, 2009. p. 195).

In practice, the approaches to collecting ownership data in household surveys do not map cleanly onto the concepts of the various rights. Household surveys tend to gather information on reported (or perception-based) ownership, documented ownership, or occasionally both. For reported ownership, the respondent(s) is/are asked who owns an asset, while for documented ownership, the respondent(s) is/are generally asked whose name(s) is/are listed as owner(s) on an ownership document such as a title, will, or receipt. ${ }^{5}$ While documented ownership is often considered the most secure, it is only relevant for certain assets, and only in places where the enforcement of the associated rights is effective.

Ownership, whether reported or documented, does not overlap consistently with the other property rights articulated above. When there are benefits such as tax reductions in India for property registered to women, this does not necessarily translate into increased control over the property by the woman whose name it is in (especially if she is unaware that her

${ }^{5}$ Only rarely do enumerators ask to see copies of the ownership documents. 
name is on the document.) And in places where documented ownership is rare, women may have the rights to manage land and obtain the economic benefits from it, even if they are not considered the owner. Thus, information on both ownership and other rights may be important.

A major challenge in measuring who owns, controls, and uses an asset is that one or more individuals or groups can hold these rights. In some cases, different people or groups may have different rights over the same asset and the benefits of ownership or control may vary depending on whether an asset is owned or controlled individually or jointly. The most common form of joint ownership is between spouses, but it can also occur between parents and children, siblings, or others. Increasing availability of data on individual and joint ownership will provide opportunities for analyses of how their impacts differ. There is a longstanding debate in the literature as to whether women are better off with individual or joint property rights, especially regarding land (Agarwal, 2003; Jackson 2003). Better data will allow us to empirically analyze these questions across contexts.

The rules and norms dictating the extent to which marriage confers property rights are an important factor influencing individual and joint property rights. A range of marital property rights exist; on one end of the spectrum is the common property regime, in which all property owned by any member of the couple is considered jointly owned. On the other end is the separation of property regime, in which marriage does not provide one with any rights to the spouse's property. In between the two extremes are the partial community property regimes, in which assets brought to the marriage or inherited by an individual during the marriage are typically individual property, but all other property acquired during the marriage is joint. Only 79 of the 173 countries analyzed in Women, Business and the Law (2016) have a full or partial community property regime, indicating that separation of property is the most common marital regime globally. A single country can have more than one marital property regime, generally based on religion, ethnicity, or region, and couples can often opt out of the default marital property regime. It is thus important to identify which regime applies to a specific couple.

Finally, the means of acquisition of property may confer or limit particular rights over it. For instance, inherited land may come with stipulations about whether it includes the right to sell or transfer it outside of the family. Whether the inheritance was natal, from one's birth family, or marital, from one's spouse, may also affect the rights.

In many countries, inheritance laws do not guarantee equal rights to sons and daughters. In addition, even where sons and daughters have equal rights, parents often choose to provide their sons with a larger inheritance. Analysis of this may be complicated by the fact that in some contexts, the dowry provided to a daughter may be viewed as her inheritance, 
although she may not control it directly (Botticini and Siow, 2003). Parents may also provide sons and daughters with different types of bequests; in the Philippines, sons are more likely to inherit land, while daughters receive more schooling (Estudillo et al., 2001). Moreover, even when daughters inherit, they may face pressure to waive these rights. For example, in many Muslim families, women give their inheritance rights to their brothers in order to maintain good relations with their birth family. Inheritance laws are also important for widows, but often discriminate against them. Thirty-five of the 173 economies assessed in Women, Business and the Law (2016) do not provide male and female surviving spouses with the same inheritance rights. In 2014, only 55 of the 160 countries included in the OECD Development Centre's Social Institutions and Gender Index (SIGI) accorded widows and widowers as well as daughters and sons the same formal and informal inheritance rights (OECD Development Centre, 2014). In sub-Saharan Africa, for example, all but five countries have implemented laws to protect women's rights to inheritance. However, according to DHS data on 15 countries in the region, only 47 percent of widows report inheriting any assets (OECD Development Centre, 2016). This discrepancy demonstrates the importance of obtaining information on both inheritance laws and practices.

Finally, we would also want information on the quality or value of women's assets compared to those owned by men. There is ample evidence that land owned by women typically tends to be smaller and/or of lower quality than that owned by men. Similarly, women's businesses tend to be smaller. Thus, simply comparing the number of landowners or business owners will miss a key dimension of the gender gap with regard to assets.

As we consider the approaches to collecting data on asset ownership, we will keep in mind these various conceptual issues, including the definition of assets and the rights over them, joint ownership contrasted with individual ownership, the rules regarding property within marriage, and the patterns of inheritance.

\section{Best Practices and Known Gaps}

In this section, we focus on what we can learn from the different approaches to collecting asset data, their relative strengths and weaknesses, and the research questions for which each is suited.

\subsection{Defining and Measuring Ownership, Control, and Use of Assets}

In any discussion of women's landownership, someone inevitably raises the issue that it women's access to land, not their ownership of land, that matters. While access is important 
for women's livelihoods, ownership may imply more secure tenure rights. Figuring out how to identify these different issues within surveys is challenging. There are several key dimensions, including security of tenure, the right to use land, and the right to keep the proceeds from the land.

When considering ownership, the first challenge is to define it. Often, we simply ask the respondent whether he or she is an owner; occasionally we also ask if there is an ownership document. The potential definitions of ownership vary across contexts. In some places, the state officially owns all the land and individuals only have use rights. Yet, when these rights are transferable, they are often similar in practice to ownership rights. In other places, the right to use the land is allocated by the community; the rights may provide long-term tenure security or may be quite vulnerable to transfer. To develop measures that are both internationally comparable and locally relevant, one approach is to define ownership as the strongest bundle of rights possible in that context.

In addition, for immovable property, information is often collected regarding whether an ownership document exists and who is listed as the owner. It is useful to identify the range of ownership documents that may be relevant in a given context, including certificates, titles, sales receipts, and wills.

To measure control and use rights, surveys have used two approaches. One is to ask about the rights that individuals have over property. These may include the right to transfer (through sales or bequests) or the right to manage or change the asset (such as by planting permanent crops or building terraces). The second is to ask about who makes decisions regarding the property, such as what to plant on the land.

While numerous studies focus on a specific set of rights, claiming that the other rights are correlated, only one paper has considered the correlation across the different rights at the plot level in multiple countries. Slavchevska et al. (2017) find that ownership, management, and control over output do not necessarily overlap and that the patterns differ markedly across the six African countries and for men and women. For each plot of land, each of the rights is defined to be held solely by a man, solely by a woman, jointly by a man and woman, or other. The overlap between ownership and management ranges from 47 percent of plots in Malawi to 84 percent in Niger. And the overlap between ownership and control over output ranges from 40 percent in Malawi to 71 percent in Uganda. This strongly suggests that these rights are distinct and may be held by different people. It would be useful to conduct a systematic study comparing these rights across a broader range of contexts. 


\subsection{Exclusive and Joint Ownership}

The property rights discussed above-ownership, control, and use-may all be held individually or jointly. ${ }^{6}$ Much of the literature on asset ownership as an indicator of women's bargaining power has not considered whether the property is owned individually or jointly. The marital regime may affect how assets acquired within marriage are owned. Further, the social norms regarding ownership within marriage may or may not match the legal regulations. Ownership may also be shared intergenerationally; the transfer of land and housing may happen over time as the parents turn over responsibility for the farm to their children.

There are two approaches to identifying individual and joint ownership, based on whether the unit of analysis is at the level of the assets or of the individuals. ${ }^{7}$ First, if the data are collected on each asset, it is possible to identify the owner(s) of each asset. Then, for each asset we know whether it is owned individually or jointly and by whom. The second approach asks each individual respondent who owns any of a specific asset type, whether they own it individually, jointly, or at least one individually and one jointly.

The Gender Asset Gap Project found that the patterns of individual and joint ownership varied widely across the three countries and across assets. Savings were almost always reported as being owned individually, while landownership patterns varied across Ecuador, Ghana, and the state of Karnataka in India (Doss et al paper in Development)

Knowing the identity of the joint owners does not necessarily tell us whether the ownership rights are shared equally among them. Ownership may be joint but not equal. Even when spouses jointly own land, women are frequently reported as having fewer rights regarding land (Doss et al., 2014; Jacobs and Kes, 2014). Additional work on the rights held by joint owners would provide useful insights into how the rights are shared.

Asset ownership is often used as an indicator of women's bargaining power. However, little research has considered whether the level of bargaining power depends on whether the asset is owned individually or jointly. As a richer set of data becomes available, this will be an important area to explore.

\footnotetext{
${ }^{6}$ In addition, some property such as land may be held by a community as common property. There are a range of issues regarding how to obtain data on common property which are beyond the scope of this study. ${ }^{7}$ We discuss the appropriate unit of analysis in more detail in Section 3.3.
} 


\subsection{Unit of Analysis}

There are two main approaches to the design of survey modules on asset ownership, depending on the appropriate unit of analysis.

The first uses the asset as the unit of analysis, identifying the owner(s) and potentially the value of each asset. The Gender Asset Gap Project, MEXA, and the surveys supported by the World Bank Living Standards Measurement Study - Integrated Surveys on Agriculture (LSMS-ISA) initiative use this approach. Consequently, the researcher can develop measures at the asset level, such as the share of land or livestock that is owned by women. For example, using the LSMS-ISA data, Doss et al. (2015) identify the share of household land owned by women. In addition, if the owners are associated with a unique ID code that allows us to match them with their individual characteristics, one can identify which individuals within the household are owners and develop incidence measures of ownership of assets by sex, age, marital status, and/or other individual attributes.

The second approach uses the individual as the unit of analysis, determining whether the individual is an owner or a right holder. The Global Findex samples and interviews individuals and asks them about their own financial assets. The DHS and the WEAI surveys use a version of this approach, each of which asks the respondent whether or not he or she owns a particular type of asset or holds particular property rights. With this approach, it is easy to create measures of the incidence of ownership by sex (and potentially by other individual characteristics if they are collected).

\subsection{Questionnaire Design}

The best practice for questionnaire design depends on the goal of the study. The questionnaire design is related to both the unit of analysis and to the selection of respondents. The approach may be a stand-alone household asset survey, a module that is part of a larger multi-purpose household survey, or a survey targeted to individuals.

One distinguishing feature is whether the questionnaire analyzes households, disaggregating the household assets by owner, or whether it analyzes individuals, without necessarily collecting information on the assets of everyone else in the household.

In the context of MEXA, Kilic and Moylan (2016) find that questionnaire design affects reporting on personal ownership of and rights to assets. MEXA used an experimental design with randomized assignment of sampled households to one of five treatment arms 
that varied in terms of their approach to questionnaire design and respondent selection. ${ }^{8}$ When subject to a questionnaire with a sole focus on respondents' personal ownership of assets (Arm 5), female respondents identify themselves as (overall and joint) owners of dwellings, livestock, and financial assets at a substantially higher rate compared to their female comparators in households in Arms 1 through 4 in which one or more respondents may have been subject to a questionnaire with a joint focus on respondents' as well as other household members' ownership of assets. For instance, within the sample of female respondents, compared to Arm 1 in which the self-identified most knowledgeable household member is the sole respondent, Arm 5 increases the incidence of joint reported dwelling ownership, on average, by 11.4 percentage points. This marginal effect is equivalent to 81 percent of the Arm 1 average for the same outcome. The comparable marginal effect associated with Arm 5 estimated within the sample of female respondents regarding joint reported financial account ownership is 3.9 percentage points, corresponding to 76 percent of the comparable average for Arm $1 .^{9}$

When multiple people are interviewed from the same household, another challenge is to determine when they are reporting on the same asset. For example, if a man says that he owns a parcel of land individually, and a woman in the same household says she owns one jointly with him, it is useful to know if they are talking about the same parcel. One way to do this is to use the approach of the Gender Asset Gap Project and begin with an asset inventory and then use it to ask respondents further questions about the specific assets identified. Respondents may be asked if they own additional assets that were not listed.

\subsection{Respondent Selection}

Research demonstrating that the choice of respondent can influence the conclusions of a study highlights the importance of understanding three key issues. First, it is critical to

\footnotetext{
${ }^{8}$ Arm 1 (standard of practice) interviewed the individual who, following the enumerator's introduction of the survey, was identified to be the "most knowledgeable" household member." This respondent was asked about the assets owned by each member of the household, exclusively or jointly with others within or outside the household, in each asset class. ${ }^{8}$ Arm 2 interviewed the randomly selected member of the principal couple while Arm 3 interviewed the principal couple together. The questionnaire for Arm 2 and Arm 3 was otherwise identical with respect to Arm 1. Arm 4 and Arm 5 each interviewed up to 4 adult household members, 18 years and above; attempts were made to conduct the interviews simultaneously. In each case, an attempt was made conduct the interview without others present. Identical to Arms 1 through 3, each respondent in an Arm 4 household was asked independently about the assets owned by each member of the household, exclusively or jointly with others within or outside the household, in each asset class. In contrast, Arm 5 only inquired about the assets owned by the respondent, exclusively or jointly with others within or outside the household, in each asset class. Another household member's potential joint ownership of an asset was identified only conditional on the respondent's identification of himself or herself as an owner of that asset.

${ }^{9}$ Among the male respondents from Arm 5 households, similar treatment effects, in terms of direction, magnitude and statistical significance, were observed in the analysis of (overall and joint) documented and (joint) economic ownership of dwellings and agricultural land as well as (joint) reported ownership of livestock and financial accounts.
} 
know who can provide the most accurate and complete information on specific topics. Second, it may be useful to know when household members would provide different information in response to the same question. For example, knowing if the husband and wife disagree about who owns a particular asset may be useful information in itself. This disagreement may be correlated with other differences in perceptions or outcomes (see, for example, Ambler et al., 2017). Finally, biases may arise due to interviewing certain individuals and not others.

The literature provides some empirical evidence on the impact of having one household member provide information about others. Fisher et al. (2010) find that when husbands alone are interviewed in Southern Malawi, they underestimate their wife's income, on average, and do not accurately estimate the total household income in most households (Fisher et al., 2010). Relatedly, Chen and Collins (2014) show that in Ghana, spouses provide poor estimates of each other's income and expenditures, both in total and by type of good.

On labor, Bardasi et al. (2011) find that female labor statistics do not differ by self/proxy reporting, but that proxy responses produce much lower male employment rates than do self-reports. Similarly, Dammert and Galdo (2013) and Janzen (2016) report significant effects of proxy respondents on child labor estimations in Peru and Tanzania, respectively, Analyzing LSMS-ISA data from Malawi and Nigeria, Palacios-Lopez et al. (2017) find opposite effects of respondent gender on reported female labor share in crop production 7 percentage points higher if the respondent is female in Malawi, lower but non-significant in Nigeria.

These studies suggest that proxy respondents may not provide adequate information on the income and labor inputs of others, including on that of their spouse. Subsequently, for asset ownership and control, the key methodological question is whether it is sufficient to interview one household member regarding the assets owned by all household members. Or perhaps a better formulation of this question is, under what circumstances is it sufficient to interview one household member versus multiple individuals? And if multiple, which household members should be interviewed? The answers depend on the analytical objective, as detailed below.

Many large-sample household surveys, including the LSMS-ISA, end up collecting individually disaggregated data regarding the ownership of assets of all household members, often through proxy respondents. Table 1 provides, by gender and age group, the rate of proxy respondent use in individual-level data collection as part of LSMS-ISAsupported household surveys. Even for a household survey program that has achieved remarkable success on many fronts since 2009 , the level of reliance on proxy respondents 
leaves significant room for improvement. In contrast, the respondents for the DHS are women and men of reproductive age and the respondents for the WEAI are the principal man and woman in each household who are each asked about their own assets. The disadvantage, in turn, is that we do not have information on ownership of and rights to physical and financial assets among non-respondents. ${ }^{10}$

There is widespread acceptance in some cultures that spouses hide assets from each other. Proxy respondents cannot report on assets that have been hidden from them. It is challenging in survey data to identify whether there are hidden assets. The Gender Asset Gap Project found relatively few assets listed in the individual interviews that were not listed in the household inventory. Additional work could be done to determine whether this is because the inventory approach results in most household assets being listed or whether respondents become fatigued and uninterested in listing additional assets. After experimenting with respondent-specific asset rosters while interviewing multiple adults in each household in the context of MEXA Arm 4 and Arm 5, Kilic and Moylan (2016) recommend the approach followed by the Gender Asset Gap project as well. Qualitative data may be needed to probe this issue. Recent work by Ambler et al (forthcoming), finds that one reason that responses about asset ownership differ between husbands and wives is asymmetric information, which may be a result of hidden assets.

There are a handful of studies that allow us to explore the implications of interviewing multiple interview targets in the same household while collecting information on individual asset ownership and control. Jacobs and Kes (2014) report that the majority of couples in the study sites in Uganda and South Africa disagree on whether land or housing are owned jointly by couples. Women are more likely than men to report joint ownership of these assets. Twyman et al. (2015) find higher levels of agreement on who jointly owns land in Ecuador, with couples agreeing that 79 percent of parcels are owned jointly. They note the existing disagreement stems from women owners reporting joint ownership on parcels to which men claim sole ownership. ${ }^{11}$

Unfortunately, there is no "gold standard" against which to measure these different approaches. For a few large assets, such as land, housing, and potentially vehicles, there may be legal records identifying the owner. However, it has not yet been possible to match administrative records with the survey results, and there are a multitude of reasons why a

\footnotetext{
${ }^{10}$ While it would be possible to ask a proxy respondent to provide information on each household member, this has not yet been done in the context of the DHS and the WEAI.

${ }^{11}$ An open empirical question is whether women are more likely to report joint ownership if the legal system supports and enforces it and less likely to do so where the enforcement is weak and customary law prevails, as in Africa.
} 
gold standard measurement approach anchored in administrative records could prove to be elusive (Kilic and Moylan, 2016). ${ }^{12}$

Qualitative fieldwork conducted in the Gender Asset Gap Project found that an individual was more likely to know about the physical assets than the financial assets owned by other household members. Thus, the survey instruments treated physical and financial assets differently. While information on physical assets was collected in both the household and individual survey instruments, data on financial assets were only collected in the individual survey instrument; each of the two respondents was asked only about his or her own financial assets, and whether these were held individually or jointly with someone else.

In the analysis of MEXA, Kilic and Moylan (2016) find that, compared to the standard practice of interviewing the most knowledgeable household member (Arm 1), interviewing multiple adult members in the same household with a questionnaire that asks each respondent to identify the assets owned by every member of the household (Arm 4), drives both female and male respondents to be more inclusive in their reporting of which household members of the opposite sex own the priority asset classes, namely dwellings, agricultural land, livestock, and financial assets. In other words, more people are listed as owners when multiple household members are interviewed.

While the magnitude of these effects is large, it is underlined by distortionary proxy respondent effects. These effects are most evident in the comparison of respondent versus proxy-respondent reporting regarding the respondent's ownership in Arm 4 households with 2 or more individual interviews. This comparison for dwellings, agricultural land, and financial accounts reveals that even when respondents, both men and women, do not claim to be owners, they may be tagged as owners by other respondents within their household. For instance, 9 percent of the female respondents that do not consider themselves to be dwelling owners are classified as joint owners by others. Similarly, 11 percent of the female respondents that do not report owning a financial account are reported to be exclusive financial account owners by others.

These types of distortionary proxy respondent effects are also observed in Arm 5 households with 2 or more interviewers, but they are markedly smaller in magnitude since

\footnotetext{
${ }^{12}$ Even with the documentation, the intra-household "truth" regarding who exerts control over a given asset may not line up with which household members are listed in the records as owners. This discrepancy could be due to (i) proxy owners intentionally being listed in the records, (ii) lags in the updating of the records following asset transfers, and/or (iii) temporal variation in intra-household control of the asset in question. Another complication, particularly related to land in Africa, could be the disconnect between between de jure legislation, which guarantees property rights irrespective of sex, and de facto recognition and implementation of property rights at the local-level. If the de facto arrangements prevail over the state laws in a way that discriminates based on gender and age and exhibit spatial variation in accordance with social norms, it is not clear that the identification of asset owner(s) based on official records would be binding at the micro-level.
} 
the Arm 5 individual questionnaire asks only about respondents' personal ownership of and rights to assets and identifies potential joint owners and/or right holders only conditional on the reported personal ownership of the respondent.

In view of these findings, together with the Arm 5 questionnaire design effects reviewed in the previous section, Kilic and Moylan (2016) recommend that researchers intending to collect intra-household information on individual ownership of and rights to physical and financial assets as part of household surveys 1) reduce the reliance on a single respondent, 2) expand the practice of interviewing multiple age-eligible individuals per household, with a focus on the members of the principal couple if a couple is present, and 3) probe directly regarding respondents' personal ownership of and rights to assets, whether exclusively or jointly with someone else, as in Arm 5. These recommendations are buttressed by previous calls for collecting data on ownership of and rights to assets at the individual level (Grown et al., 2005; Doss et al., 2011).

Ultimately, the purpose of the survey may shape the choices regarding whom to interview. If we want to understand the bargaining power or empowerment effects of asset ownership, then asking individuals about their own ownership or rights over assets is likely to best capture their perceptions, in line with the empirical evidence reviewed above. For intrahousehold analyses, multiple age-eligible individuals should be interviewed, with the possibility of (i) attempting to interview all age-eligible household members as in MEXA or (ii) focusing on the members of the principal couple in the married/co-habitating household sub-population or (iii) selecting a random age-eligible household member and his/her partner if applicable across the entire household population. ${ }^{13}$

If multiple people are interviewed for intra-household analysis, there may be multiple responses about the same asset. There are different ways to handle this, depending on the research question. The fallback option could be to accept each person's response as to whether they are an owner. This is particularly appropriate when studying women's empowerment. An alternative option is to reconcile the responses so that one owner or set of owners is identified for each asset. The Gender Asset Gap Project, particularly for Ecuador, used information on the marital property laws, the respondents' marital status, and when the asset was acquired to report the owner(s) when there was a discrepancy among respondents. This approach was necessary to calculate the gender wealth gap without double counting.

\footnotetext{
${ }^{13}$ The UN EDGE international guidelines on individual-level measurement of asset ownership and control are expected to expand on these scenarios and their implications for fieldwork design and sampling.
} 


\subsection{Quantification, Valuation, and Quality Assessment}

While simply identifying the owners of assets allows us to calculate measures of the incidence of asset ownership, we often want more information about people's assets such as quantity, value, and/or quality.

Identifying the quantity owned of most assets is relatively straightforward. Survey designers use two approaches, depending on the unit of analysis, as discussed in Section 3.3. The first approach uses the asset as the unit of analysis and identifies the owners of each asset. It is then possible to calculate the quantity owned by each individual ${ }^{14}$ and by each combination of joint owners. A second approach, which can be employed when the individual is the unit of analysis, is to ask each respondent how many of each asset they own, whether individually or jointly with someone else. These two approaches can also be used to assign value.

There are, however, several challenges to obtaining good measures of asset values. For consistent answers, one should specify the measure of value. Asking the original purchase price and the year of acquisition facilitates calculation of the depreciated value, assuming a typical amount of wear. A common approach is to ask the price that would be received if the asset were sold, assuming that there are markets for such goods and the respondent is aware of the market price. When sales markets are limited, rental markets for land or housing may provide insights into value. A final measure is the cost to replace the asset. Based on analysis in three countries, the Gender Asset Gap Project recommends using the price that would be received if the asset were sold at the time of the survey.

When markets are thin or nonexistent, it may be hard for respondents to provide a value. For example, rural houses that are constructed by household members may not have an explicit market value. In addition, respondents may be unwilling to name a price if they think the enumerator is interested in purchasing it. In such case, they may want to respond that it is invaluable.

A further challenge is that there may be some systematic bias in reported values depending on who is asked. Doss et al. (2018), using the Gender Asset Gap Project data, find that for housing, the values provided by women have a narrower distribution than those provided by men, even for couples who are reporting on the same dwelling. Thus, respondent selection may influence the size of the calculated gender wealth gap. There is much more scope for understanding how patterns of reported values vary systematically in accordance with sex and other individual attributes.

\footnotetext{
14 At least one exception in reliable self-reported asset quantification is farmer-reported land area measurement (Carletto et al., 2015; 2016).
} 
We would expect that the value is associated with quality for assets for which there are robust markets. Given the difficulties associated with obtaining monetary values for some assets, it may be possible to obtain information on the characteristics of the asset. For example, many surveys collect data on housing characteristics such as size, amenities, construction materials, etc. This allows for the construction of a housing quality index that may be compared across owners. It may be possible to collect data on quality aspects of other assets as well. Pouw (2012) suggests that researchers could monitor changes in living standards by assessing improvements in clothing and farm implements in addition to housing.

Finally, to understand gender gaps in land ownership, it is useful to have information on land areas. Carletto et al. (2015), using the LSMS-ISA data for 4 African countries, document substantial measurement errors in farmer-reported plot areas compared to the GPS-based area measures for the same plots. These differences result in underestimation of land inequality, as measured by the Gini coefficient, and biased estimates of the relationship between land and productivity. Carletto et al. (2016) further show that GPS provides highly accurate land area measures compared to the gold standard methodology of using compass and rope and does so across the entire distribution of plot areas. Although research has not addressed whether men and women provide systematically different estimates of land area, using GPS would avoid these potential biases.

\section{Conclusions and moving forward}

While there is strong evidence that ownership, control, and use of assets is important for creating livelihoods, reducing vulnerability, and increasing voice within the household and community, there are still numerous gaps in our knowledge about how best to obtain these data and what aspects of the data are most relevant.

Many research questions remain. We can begin to answer some of them with existing data, while others will require collection of additional data. First, to what extent are the various rights regarding assets correlated? For example, in which contexts are the ownership, management, and rights to the economic benefits of land all held by the same person? When are they held by different people? Which of these rights is most closely associated with the benefits of ownership? If women have access and control rights, does providing them with ownership rights result in any changes in their well-being? Which assets matter for which outcomes? As land becomes scarcer, it may become even more difficult to secure women's land rights. However, to what extent can women's rights to housing or businesses provide similar levels of security, empowerment, and/or livelihoods? Further, there is a 
dearth of evidence on the dynamics, rather than snapshots, of gender asset gaps, and gender-differentiated overlap amongst asset ownership and rights constructs.

A recent literature suggests that there are asset poverty thresholds, below which it is difficult for a household to move out of poverty (see Kraay and McKenzie 2014 for a review). The empirical results are mixed, but the concept has had a significant influence on policy. It suggests that if people have below the threshold level of assets, they will need to sell them to cover basic expenses. However, above the threshold, they will be able to generate income and begin to move out of poverty. Yet the question of whether there is a threshold level of assets for individuals within households remains unexplored. Is there some minimum share of assets that a woman must own to have a voice in household decision-making or to allow her an adequate fallback position? ${ }^{15}$

A third set of questions is related to individual and joint ownership of assets. These questions tie in with an earlier debate regarding whether women's individual land rights should be the focus of policy (Agarwal 2003) or whether women's land rights may be strengthened by recognizing their embeddedness in broader social systems that provide forms of joint ownership (Jackson 2003). From an economic bargaining model perspective, individual asset ownership may provide a better fallback position than jointly owned assets, particularly immovable assets such as land. If assets are owned jointly, it may be difficult to obtain one's share of the value when leaving. On the other hand, joint property rights may be embedded in deeper social relationships that provide added benefits. There is substantial scope for further analyses of the relationships of individual and joint property rights with a wide range of outcomes. ${ }^{16}$

A fourth set of issues relates to the need to understand the patterns of asset ownership and dispossession in the context of conflict and displacement as well as environmental crises and natural disasters. Much of the existing work on how to protect assets in these situations does not explicitly consider gender issues or use sex-disaggregated data. These situations present challenges to collecting asset ownership data. These issues become more complex

\footnotetext{
${ }^{16}$ A related strand of research is interested in relative household and individual welfare gains associated with (1) balancing the relative bargaining power of spouses versus (2) enhancing intra-household cooperation among them. While the latter may be proxied by individual-level data on joint asset ownership, the comparable scope of information on exclusive ownership could help define the former. McCarthy and Kilic (2017) develop a non-cooperative bargaining model that presents conditions under which relatively large gains would be expected from moving to more equitable bargaining power versus achieving intra-household cooperation. They test their model's predictions using the LSMS-ISA data from Malawi, and specifically the individual-disaggregated data on control of income. The authors find that relative to increasing wives' bargaining power (defined as the share of total disjoint (male + female) income that is under female control), improving cooperation between spouses (defined as the share of total household income that is under joint control) exerts larger and statistically significant positive impacts on total household income and consumption expenditures per capita, as well as the share of household consumption devoted to public goods.
} 
when those displaced include children (Joireman, 2018). Collecting data in times of conflict can be particularly challenging, but with detailed asset data collected before a conflict erupts, we may be able to follow these individuals through the conflict and reconstruction. Similarly, it may be possible to follow people through other types of crises, to understand the relationship between assets and welfare in other contexts. McPeak, Little and Doss (2011) analyze the impact of a drought and recovery in Northern Kenya and Southern Ethiopia among pastoralists, with some attention to gender issues. Most of the impacts were around livestock losses, since the pastoralists had relatively few other assets.

A final set of questions are methodological in nature and require further field experimentation/data collection and the use of mixed research methods. For example, qualitative work will be needed to complement our analyses of overlaps amongst asset ownership and rights constructs and enhance our understanding of how men and women perceive and value joint versus individual ownership, control, and use of assets. Further, the body of evidence is thin on how the framing of questions on ownership and rights could affect survey responses, and whether the effects vary by gender and across countries with different marital and inheritance regimes. Potential gender differences in the comprehension and interpretation of these questions is a related area of methodological research that could shed light on the drivers of gender differences in survey responses and that could be explored through cognitive interviewing pilots in the field. Additionally, we do not yet have a robust evidence base on whether individual's incentives to centralize their responses around various social norms might vary with (1) the gender of the enumerator, and (2) whether a face-to-face interview is conducted in private or in the presence of a spouse or other household members. Finally, a subset of outstanding methodological questions pertains to asset valuation. While objectively-verifiable asset valuation that could be pursued in household surveys will remain a long-term goal, as noted above, additional research is needed on the extent and correlates of differences in how men and women value assets in individual interviews.

Much of the recent work discussed in this paper clearly demonstrates the importance and feasibility of collecting sex-disaggregated asset data. Now that the frontier has expanded, it is much more feasible for asset data to be routinely sex-disaggregated in both national surveys and project impact evaluation surveys. In addition, a robust research agenda poses additional conceptual and methodological challenges to better understanding of the roles of individual and joint ownership. 


\section{References}

Agarwal, B. (2003). "Gender and land rights revisited: exploring new prospects via the state, family and market." Journal of Agrarian Change, 3.1-2, pp. 84-224.

Allendorf, K. (2007). "Do women's land rights promote empowerment and child health in Nepal?" World Development, 35.11, pp. 1975-1988.

Ambler, K., Doss, C., Kieran, C., and Passarelli, S. (forthcoming). "He says, she says: Exploring patterns of spousal agreement in Bangladesh." Economic Development and Cultural Change.

Bardasi, E., Beegle, K., Dillon, A., and Serneels, P. (2011). "Do labor statistics depend on how and to whom the questions are asked? Results from a survey experiment in Tanzania." World Bank Economic Review, 25.3, pp. 418-447.

Beegle, K., Frankenberg, E., and Thomas, D. (2001). "Bargaining power within couples and use of prenatal and delivery care in Indonesia." Studies in Family Planning, 32.2, pp. 130-146.

CAPRi (CGIAR Systemwide Program on Collective Action and Property Rights). (2010). Resources, rights, and cooperation: a sourcebook on property rights and collective action for sustainable development. Washington, DC: International Food Policy Research Institute (IFPRI).

Carletto, C., Gourlay, S., Murray, S., and Zezza, A. (2016). "Cheaper, faster, and more than good enough. Is GPS the new gold standard in land area measurement?" World Bank Policy Research Working Paper No. 7759.

Carletto, C., Gourlay, S., and Winters, P. (2015). "From guesstimates to GPStimates: land area measurement and implications for agricultural analysis." Journal of African Economies, 24.5, pp. 593-628.

Chen, J., and Collins, L. (2014). "Let's talk about the money: spousal communication, expenditures, and farm production. American Journal of Agricultural Economics, 96.5, pp. 1272-1290.

Dammert, A., and Galdo, J. (2013). "Child labor variation by type of respondent: Evidence from a Large-Scale Study.” World Development 51, pp. 207-220.

Deere, C. D., and Doss, C. R. (2006). "The gender asset gap: what do we know and why does it matter?" Feminist Economics, 12.1-2, pp. 1-50.

Deere, C. D., Alvarado, G. E., and Twyman, J. (2012). "Gender inequality in asset ownership in Latin America: female owners vs. household heads." Development and Change, 43.2, pp. 505-530.

Deininger, K., Goyal, A., and Nagarajan, H. (2010). "Inheritance law reform and women's access to capital: evidence from India's Hindu succession act." World Bank Policy Research Working Paper No. 5338.

Doss, C. (2006). "The effects of intrahousehold property ownership on expenditure patterns in Ghana." Journal of African Economies, 15.1, pp. 149-180. 
Doss, C. R. (2017). Women and agricultural productivity: Reframing the Issues, (February), 1-16. http://doi.org/10.1111/dpr.12243

Doss, C., Grown, C., and Deere, C.D. (2008). "Gender and asset ownership: a guide to collecting individual level data.” World Bank Policy Research Working Paper No. 4704.

Doss, C., Deere, C. D., Suchitra J. Y., Oduro, A. D., and Hillesland, M. (2011) "Lessons from the field: implementing individual asset surveys in Ecuador, Ghana, India and Uganda." Retrieved on May 8, 2017 from http://tinyurl.com/assetgap .

Doss, C., Meinzen-Dick, R., and Bomuhangi, A. (2014). "Who owns the land? perspectives from rural Ugandans and implications for large-scale land acquisitions." Feminist Economics, 20.1, pp. 76-100.

Doss, C. R., Deere, C. D., Oduro, A. D., \& Swaminathan, H. (2014). The Gender Asset and Wealth Gaps. Development, 57(3-4). http://doi.org/10.1057/dev.2015.10.

Doss, C., Kovarik, C., Peterman, A., Quisumbing, A., van den Bold, M. (2015). "Gender inequalities in ownership and control of land in Africa: myth and reality." Agricultural Economics, 46, pp. 403-434.

Doss, C. R., Catanzarite, Z., Baah-boateng, W., Swaminathan, H., Diana, C., Boakyeyiadom, L., \& Suchitra, J. Y. (2018). Do men and women estimate property values differently? World Development, 107, 75-86.

Duflo, E. (2003). "Grandmothers and granddaughters: old-age pensions and intrahousehold allocation in South Africa." World Bank Economic Review, 17.1, pp. 1-25.

Estudillo, J., Quisumbing, A., and Otsuka, K. (2001). "Gender differences in land inheritance, schooling and lifetime income: evidence from the rural Philippines." Journal of Development Studies, 37.4, pp. 23-48.

Fisher, M., Reimer, J. J., and Carr, E. R. (2010). "Who should be interviewed in surveys of household income?" World Development, 38.7, pp. 966-973.

Goldstein, M., and Udry, C. (2008). "The profits of power: land rights and agricultural investment in Ghana." Journal of Political Economy, 116.2, pp. 981-1022.

Gender, Assets, and Agriculture Project. (2014). A Toolkit on Collecting Gender \& Assets Data in Qualitative \& Quantitative Program Evaluations. Washington, DC: International Food Policy Research Institute. http://gaap.ifpri.info/files/2010/12/GAAP_Toolkit_Update_FINAL.pdf

Grown, C., and Gupta, G.R. (2005). Taking action: achieving gender equality and the Millennium Development Goals. New York: Earthscan Publications.

Haddad, L., Hoddinott, J., and Alderman, H. (1997). Intrahousehold resource allocation in developing countries: models, methods, and policies. Baltimore, Maryland: Johns Hopkins University Press.

Marya Hillesland (2018). "Investigating the gender wealth gap in Ghana." Oxford Development Studies, DOI: 10.1080/13600818.2018.1498473 
Jackson, C. (2003). "Gender analysis of land: beyond land rights for women?" Journal of Agrarian Change, 3.4, pp. 453-480.

Jacobs, K., and Kes, A. (2014). "The ambiguity of joint asset ownership: cautionary tales from Uganda and South Africa." Feminist Economics, 21.3, pp. 23-55.

Janzen, S.A. (2016). "Child labor measurement: Whom should we ask?" International Labour Review.

Johnson, N., Kovarik, C., Meinzen-Dick, R., Njuki, J., and Quisumbing, A. (2016). "Gender, assets, and agricultural development: lessons from eight projects." World Development, 83, pp. 295-311.

Joireman, Sandra F., "Protecting future rights for future citizens: children's property rights in fragile environments," Oxford Development Studies. Forthcoming in 2018.

Kilic, T., and Moylan, H. (2016). "Methodological experiment on measuring asset ownership from a gender perspective (MEXA) technical report." Washington, DC: World Bank. Retrieved on May 8, 2017 from http://tinyurl.com/mexareport.

Kraay, A., and McKenzie, D. (2014). "Do poverty traps exist?" Journal of Economic Perspectives, 28.3, pp. 127-148.

McCarthy, N., and Kilic, T. (2017). "Stronger together: intra-household cooperation and household welfare in Malawi." World Bank Policy Research Working Paper No. 8043.

McPeak, J., Little, P. and Doss, C. (2011) "Risk and Social Change in an African Rural Economy: Livelihoods in Pastoralist Communities." London: Routledge.

Meinzen-Dick, R., Johnson, N., Quisumbing, A., Njuki, J., Behrman, J., Rubin, D., Peterman, A., and Waithanji, E. (2014). "The gender asset gap and its implications for agricultural and rural development." In A. R. Quisumbing, R. Meinzen-Dick, T. L. Raney, A. Croppenstedt, J. A. Behrman, and A. Peterman (Eds), Gender and Agriculture: Closing the Knowledge Gap, Springer.

Menon, N., Rodgers, Y., and Nguyen, H., (2014). "Women's land rights and children's human capital in Vietnam." World Development, 54, pp. 18-31.

OECD Development Center (2014). "Social Institutions and Gender Index (SIGI) 2014 Synthesis Report." Retrieved on September 6, 2018 from http://www.oecd.org/dev/development-gender/BrochureSIGI2015-web.pdf.

OECD Development Center (2016). "Sub-Saharan Africa: SIGI Regional Report." Retrieved on September 6, 2018 from

https://www.genderindex.org/wpcontent/uploads/files/docs/Brochure_SIGI_SSA_web.pdf.I

O'Sullivan, Michael. 2017. "Gender and Property Rights in Sub-Saharan Africa: A Review of Constraints and Effective Interventions." World Bank Policy Research Working Paper No. 8250.

Palacios-Lopez, A., Christiansen, L., and Kilic, T. (2017). "How much of the labor in African agriculture is provided by women?" Food Policy, 67, pp. 52-63. 
Pouw, N. (2012). "Poverty and Asset Accumulation among Smallholder Farmers in Uganda." In Nicky Pouw and Isa Baud (Eds.), Local Governance and Poverty in Developing Nations (pp. 52-72). New York, NY: Routledge.

Quisumbing, A., Payongayong, E., Aidoo, J.B., and Otsuka, K. (2001). "Women's land rights in the transition to individualized ownership: implications for the management of tree resources in western Ghana." Economic Development and Cultural Change, 50.1, pp. 157-182.

Quisumbing, A., and Maluccio, J. (2003). "Resources at marriage and intrahousehold allocation: evidence from Bangladesh, Ethiopia, Indonesia, and South Africa." Oxford Bulletin of Economics and Statistics, 65.3, pp. 283-327.

Quisumbing, A., Kumar, N., and Behrman, J. (2011). "Do shocks affect men's and women's assets differently? a review of literature and new evidence from Bangladesh and Uganda." IFPRI Discussion Paper No. 1113.

Ruel, E., and Hauser, R. (2013).” Explaining the gender wealth gap.” Demography, 50.4., pp. 1155-1176.

Santos, F., Fletschner, D., Savath, V. and Peterman, A. (2014). Can government-allocated land contribute to food security? Intrahousehold analysis of West Bengal's microplot allocation program. World Development 64: 860-872.

Schlager and Ostrom (1992). "Property rights regimes and natural resources: a conceptual analysis." Land Economics, 68.3, pp. 249-262.

Sierminska, E., Frick, J., and Grabka, M. (2010). "Examining the gender wealth gap." Oxford Economic Papers, 62(4), 669-690. http://doi.org/10.1093/oep/gpq007

Slavchevska, V., De la O, A., Brunelli, C., and Doss, C. (2017). "Beyond Ownership: Women's and Men's Land Rights in sub-Saharan Africa." Paper presented at the World Bank Conference on Land and Poverty, Washington, DC. March 2017.

Scoones, I. (1998). "Sustainable rural livelihoods: a framework for analysis." Institute of Development Studies Working Paper No. 72.

Thomas, D. (1990). "Intrahousehold resource allocation in developing countries: An inferential approach." Journal of Human Resources 25.4, pp. 635-64.

Twyman, U., Useche, P., and Deere, C. D. (2015). "Gendered perceptions of land ownership and agricultural decision-making in Ecuador: who are the farm managers?" Land Economics, 91.3, pp. 479-500.

United Nations Statistics (2009). System of national accounts. New York, NY: United Nations. Retrieved on May 8, 2017 from http://tinyurl.com/nataccounts.

Warren, T. (2006). "Moving beyond the gender wealth gap: on gender, class, ethnicity, and wealth inequalities in the UK." Feminist Economics, 12.1-2, pp. 195- 219.

Women, Business and the Law (2016). Retrieved on May 8, 2017 from http://tinyurl.com/womenbusinesslaw. 
Table 1: Rate of Proxy Respondent Use for Individual-Level Labor Data Collection in LSMS-ISA,

\begin{tabular}{lccc|ccc|ccc}
\multicolumn{10}{c}{ by Gender and Age Group } \\
\hline & \multicolumn{3}{c|}{ Age Group: 15-24 } & \multicolumn{3}{c|}{ Age Group: 15-64 } & \multicolumn{3}{c}{ Age Group: 18+ } \\
\cline { 2 - 10 } Malawi (2017) & Overall & Male & Female & Overall & Male & Female & Overall & Male & Female \\
\cline { 2 - 11 } Niger (2014) & 64.1 & 72.2 & 56.7 & 45.0 & 55.1 & 36.1 & 37.9 & 48.1 & 29.1 \\
Nigeria (2016) & 44.8 & 43.1 & 46.5 & 42.0 & 37.8 & 45.6 & 41.1 & 36.4 & 45.1 \\
Tanzania (2013) & 34.1 & 35.3 & 32.7 & 24.2 & 27.9 & 20.9 & 24.2 & 27.9 & 20.9 \\
Mali (2014) & 99.0 & 42.9 & 28.1 & 24.1 & 30.3 & 18.3 & 21.6 & 27.3 & 16.4 \\
Uganda (2014) & 76.8 & 98.2 & 99.8 & 84.9 & 70.5 & 98.1 & 81.1 & 63.0 & 97.6 \\
\hline
\end{tabular}

Notes: The gender difference in the rate of proxy respondent use in each country age group is statistically significant at the 1 percent

level, with the exception of Nigeria Age Group 15-24 (5 percent significance), Niger Age Group 15-24 (10 percent significance). The

estimates are based on the latest LSMS-ISA-supported survey round in each country. 